\title{
Propionate alleviates fatty acid-induced mitochondrial dysfunction, oxidative stress, and apoptosis by upregulating PPARG coactivator 1 alpha in hepatocytes
}

\author{
Xinghui Wang, ${ }^{1} \odot$ Mengyao Zhu, ${ }^{1} \odot$ Juan J. Loor, ${ }^{2} \odot$ Qianming Jiang, ${ }^{2} \odot$ Yiwei Zhu, ${ }^{1}$ Wei Li, ${ }^{1}$ Xiliang Du, ${ }^{1} \odot$ \\ Yuxiang Song, ${ }^{1}$ Wenwen Gao, ${ }^{1} \odot$ Lin Lei, ${ }^{1}$ Jianguo Wang, ${ }^{3}{ }^{\oplus}$ Guowen Liu, ${ }^{1} \odot$ and Xinwei $\mathrm{Li}^{1 *}{ }^{1 *}$ \\ ${ }^{1}$ State Key Laboratory for Zoonotic Diseases, Ministry of Education, College of Veterinary Medicine, Jilin University, 5333 Xi'an Road, Changchun, \\ 130062, Jilin, China \\ ${ }^{2}$ Mammalian NutriPhysioGenomics, Department of Animal Sciences and Division of Nutritional Sciences, University of Illinois, Urbana 61801 \\ ${ }^{3}$ College of Veterinary Medicine, Northwest A\&F University, Yangling, Shaanxi 712100, China
}

\begin{abstract}
Reduced feed intake during the transition period renders cows unable to meet their energy needs for maintenance and lactation, leading to a state of negative energy balance. Severe negative energy balance initiates fat mobilization and increases circulating levels of free fatty acids (FFA), which could induce hepatic mitochondrial dysfunction, oxidative stress, and apoptosis. Enhancing the hepatic supply of propionate (major gluconeogenic substrate) is a feasible preventive and therapeutic strategy to alleviate hepatic metabolic disorders during the transition period. Whether propionate supply affects pathways beyond gluconeogenesis during high FFA loads is not well known. Thus, the objective of this study was to investigate whether propionate supply could protect calf hepatocytes from FFA-induced mitochondrial dysfunction, oxidative stress, and apoptosis. Hepatocytes were isolated from 5 healthy calves ( $1 \mathrm{~d}$ old, female, $30-40 \mathrm{~kg}$, fasting) and treated with various concentrations of propionate $(0,1$, 2, and $4 \mathrm{~m} M$ propionate for $12 \mathrm{~h}$ ) or for different times ( $2 \mathrm{~m} M$ propionate for $0,3,6,12$ and $24 \mathrm{~h}$ ). Furthermore, hepatocytes were treated with propionate $(2 \mathrm{mM})$, fatty acids $(1.2 \mathrm{mM})$, or both for $12 \mathrm{~h}$ with or without $50 \mathrm{nM}$ PGC-1 $\alpha$ (peroxisome proliferator-activated receptorgamma coactivator-1 alpha) small interfering RNA. Compared with the control group, protein abundance of PGC-1 $\alpha$ was greater with 2 and $4 \mathrm{~m} M$ propionate treatment groups. Furthermore, protein abundance of TFAM (mitochondrial function marker mitochondrial transcription factor A) and VDAC1 (voltage-dependent anion channel 1) was greater with 1,2 , and $4 \mathrm{mM}$ propionate, and COX4 (cyclooxygenase 4) was greater with 2 and $4 \mathrm{mM}$ propionate groups. In addition, pro-
\end{abstract}

Received August 24, 2021.

Accepted November 21, 2021.

*Corresponding author: lixinwei100@126.com pionate supply led to an increase in protein abundance of PGC-1 $\alpha$, TFAM, VDAC1, and COX4 over time. Flow cytometry revealed that propionate treatment increased the number of mitochondria in hepatocytes compared with control group, but inhibition of PGC$1 \alpha$ abolished these beneficial effects. The lower protein abundance of PGC- $1 \alpha$, TFAM, COX4, and VDAC1 and activities of superoxide dismutase and glutathione peroxidase, along with greater production of reactive oxygen species, malondialdehyde, and apoptosis rate in response to treatment with high concentrations of FFA suggested an impairment of mitochondrial function and induction of oxidative stress and apoptosis. In contrast, propionate treatment hastened these negative effects. Knockdown of PGC-1 $\alpha$ by small interfering RNA impeded the beneficial role of propionate on FFA-induced mitochondrial dysfunction, oxidative stress, and apoptosis. Overall, results demonstrated that propionate supply alleviates mitochondrial dysfunction, oxidative stress, and apoptosis in FFA-treated calf hepatocytes by upregulating PGC-1 $\alpha$. Together, the data suggest that PGC-1 $\alpha$ may be a promising target for preventing or improving hepatic function during periods such as the transition into lactation where the FFA load on the liver increases.

Key words: propionate, mitochondria dysfunction, oxidative stress, apoptosis

\section{INTRODUCTION}

During early lactation, most dairy cows experience a state of negative energy balance (NEB) caused by decreased DMI and increased demands for energy to support milk production (Hayirli et al., 2002). The onset of NEB initiates fat mobilization and a subsequent increase in blood concentrations of free fatty acids (FFA; Liu et al., 2014), which often result in development of ketosis. Studies in mice and ketotic cows suggest that high concentrations of FFA lead 
to lipotoxicity, which induces liver damage (Miura et al., 2013; Dong et al., 2019). Mechanistically, excessive FFA in ketotic cows impairs hepatic mitochondrial function and leads to overproduction of reactive oxygen species (ROS), which further induces oxidative stress and apoptosis (Gao et al., 2018; Li et al., 2020). Thus, exploring therapeutic strategies to alleviate lipotoxicity induced by high concentrations of circulating FFA in dairy cows may be an effective approach for preventing hepatic metabolic disorders and injury.

Mitochondria orchestrate hepatic energy metabolism through coordinated action of pathways such as glycolysis, tricarboxylic acid cycle, ATP synthesis, and $\beta$-oxidation (Koliaki et al., 2015). Formation of ROS without a proper antioxidant response when the activity of these pathways increases can lead to progression of hepatic metabolic disorders and pathological injury including mitochondrial damage. The latter also can lead to overproduction of ROS and a state of oxidative stress, apoptosis, and aggravation of the clearance of lipid from the liver (Huc et al., 2012; Perier et al., 2012; Kim et al., 2019; Lee et al., 2019). At least in nonruminants, PGC- $1 \alpha$ (peroxisome proliferatoractivated receptor-gamma coactivator-1 alpha) is a critical regulator of mitochondrial function (Kelly and Scarpulla, 2004). One of its key targets is TFAM (mitochondrial transcription factor A), a key regulator of mitochondrial DNA copy number that helps maintain mitochondrial DNA integrity, mitochondrial biogenesis, and function (Picca and Lezza, 2015). Data from mice demonstrated that PGC-1 $\alpha$ prevented apoptosis by reducing ROS production and enhancing mitochondrial function (Jiang et al., 2013). In calf hepatocytes, high concentrations of FFA inhibited PGC-1a expression, and PGC-1 $\alpha$ overexpression ameliorated FFA-induced mitochondrial dysfunction and oxidative stress (Gao et al., 2018). Thus, PGC-1 $\alpha$ may be an effective therapeutic target for hepatic pathologic injury in ketosis induced by high concentrations of FFA.

The main source of circulating glucose in ruminants is gluconeogenesis, with propionic acid (produced in the rumen) being the primary substrate utilized in liver (Aschenbach et al., 2010). Supplementation of propylene glycol to dairy cows after parturition is a common preventive treatment for NEB-induced shortfalls in circulating glucose that often lead to metabolic disorders (Bobe et al., 2004). There is also evidence that propionate prevents apoptosis induced by fatty acids in mouse and human islets in vitro (Pingitore et al., 2017, 2019). Whether propionate can ameliorate lipotoxicity in response to increased influx of FFA into hepatocytes in dairy cows remains unknown. If proven true, a beneficial effect of propionate on the preven- tion and treatment of ketosis could be further clarified. Thus, the aim of this study was to investigate the role and mechanisms whereby propionate could help alleviate fatty acid-induced mitochondrial dysfunction, oxidative stress, and apoptosis in bovine hepatocytes.

\section{MATERIALS AND METHODS}

\section{Hepatocyte Isolation and Culture}

The protocol was approved by the Ethics Committee on the Use and Care of Animals of Jilin University [Changchun, China, 2018 clinical trial (2018-35892)]. Primary hepatocytes were isolated from 5 Holstein calves ( $1 \mathrm{~d}$ old, female, 30-40 kg, fasting, rectal temperature: $38.7-39.7^{\circ} \mathrm{C}$, healthy) purchased from a commercial dairy farm (Changchun, China). Methods for isolation of hepatocytes were described in a previous study (Zhang et al., 2012; Liu et al., 2014). In brief, the liver (caudate process) was quickly removed from calves after they were anesthetized using thiamylal sodium and injected heparin into the jugular vein. The bloodstains on the liver surface were removed with perfusion solution A $\left(37^{\circ} \mathrm{C}\right)$. Blood vessels were intubated, and the liver was perfused with perfusion solution $\mathrm{A}$ at a flow rate of $50 \mathrm{~mL} / \mathrm{min}$ for $15 \mathrm{~min}$. Then, liver was perfused with perfusion solution $\mathrm{B}\left(37^{\circ} \mathrm{C}\right)$ at the same flow rate until the liquid became clear. Subsequently, liver was digested with collagenase IV solution $(0.1 \mathrm{~g}$ of collagenase IV dissolved in $0.5 \mathrm{~L}$ of perfusion solution $\mathrm{B}, \mathrm{pH} 7.2-7.4,37^{\circ} \mathrm{C}$ ) at a flow rate of $20 \mathrm{~mL} / \mathrm{min}$ for 15 to $20 \mathrm{~min}$. After digestion, the liver was moved to a sterile flat plate, and fetal bovine serum (FBS; Hyclone Laboratories) was added to terminate collagenase digestion.

The liver was cut open, and the liver capsule, blood vessels, fat, and connective tissue were removed using forceps and scissors. The tissue suspension was filtered sequentially with 100 -mesh $(150 \mu \mathrm{m})$ and 200 -mesh $(75$ $\mu \mathrm{m})$ cell sieves. The hepatic cells suspension was then washed twice in RPMI-1640 basic medium (SH30027.02, Hyclone Laboratories) and centrifuged for 5 min at 500 $\times g$ at $4^{\circ} \mathrm{C}$. Trypan blue dye (Sigma-Aldrich) exclusion method was used to assess cell viability. The cell density was adjusted to $1 \times 10^{6}$ cells $/ \mathrm{mL}$, and the hepatocyte suspension was seeded into a 6 -well tissue culture plate (2 mL per well) using adherent medium (RPMI-1640 basic medium supplemented with $10 \% \mathrm{FBS}, 10^{-6} \mathrm{~mol} / \mathrm{L}$ of insulin, $10^{-6} \mathrm{~mol} / \mathrm{L}$ of dexamethasone, $10 \mu \mathrm{g} / \mathrm{mL}$ of vitamin $\mathrm{C}$ ) and cultured at $37^{\circ} \mathrm{C}$ in $5 \% \mathrm{CO}_{2}$. After $4 \mathrm{~h}$, the medium was replaced with growth medium (RPMI1640 basic medium supplemented with 10\% FBS). The medium was replaced with fresh medium every 
$24 \mathrm{~h}$, and hepatocytes were subjected to treatments $48 \mathrm{~h}$ later. The perfusion solution, digestion solution, adherent medium, and growth medium were prepared as described in our previous study (Liu et al., 2014).

\section{Preparation and Treatment of Fatty Acids and Propionate}

Hepatocytes were serum-starved overnight, and cells were then maintained in RPMI-1640 basic medium containing 2\% BSA. Propionate was obtained from Sigma (P1880, Sigma-Aldrich) with a purity of more than $99.0 \%$. The composition and concentration of fatty acids used in this study were chosen according to the normal and pathological hematology standards for dairy cows with ketosis (Bertics et al., 1992). Stock fatty acid solution was prepared as previously described (Li et al., 2012). The fatty acids were diluted in $0.1 \mathrm{M}$ $\mathrm{KOH}$ at $60^{\circ} \mathrm{C}$, and the $\mathrm{pH}$ of the fatty acid solution was adjusted to 7.4 with hydrochloric acid $(1 M)$. The stock fatty acid $(52.7 \mathrm{mM})$ solution included oleic acid (22.9 $\mathrm{m} M)$, linoleic acid $(2.6 \mathrm{mM})$, palmitic acid $(16.8 \mathrm{mM})$, stearic acid $(7.6 \mathrm{mM})$, and palmitoleic acid $(2.8 \mathrm{mM}$; Sigma-Aldrich). For temporal experiments, hepatocytes were treated with $2 \mathrm{mM}$ propionate for $0,3,6,12$ and $24 \mathrm{~h}$. In the dose-response experiments, hepatocytes were treated with $0,1,2$, and $4 \mathrm{~m} M$ propionate for $12 \mathrm{~h}$ (Gao et al., 2021). Furthermore, hepatocytes were also treated with propionate $(2 \mathrm{mM})$, fatty acids $(1.2 \mathrm{mM})$, or both of them for $12 \mathrm{~h}$ with or without $50 \mathrm{n} M$ PGC$1 \alpha$ small interfering RNA (siRNA). All of the experiments were repeated in 5 calves. At least 3 biological replicates of all the experiments were performed in each calf, and 3 technical replicates (parallel measurements) were performed in each biological replicate.

\section{PGC-1a Gene Silencing in Hepatocytes}

A total of $1 \times 10^{6}$ hepatocytes were plated in 6 -well plates maintained in RPMI-1640 basic medium. The PGC-1 $\alpha$ siRNA (50 and $75 \mathrm{n} M$ ) and negative control siRNA were transfected into cells with Lipofectamine 2000 (11668030; Invitrogen, Ltd.). The PGC-1 $\alpha$ siRNA and negative control siRNA were purchased from Beijing RiboBio Co., Ltd. Six hours later, RPMI-1640 basic medium was replaced by growth medium. After incubation at $37^{\circ} \mathrm{C}$ for $42 \mathrm{~h}$, hepatocytes were harvested for quantitative real-time PCR, protein abundance, or flow cytometry (Becton Dickinson, Franklin Lakes). The target sequences of PGC- $1 \alpha$ siRNA were as follows: (1) GCTCAGAGCTTCTCAAGTA, (2) GACTATTGTCAGTCAATTA, and (3) GGCAGTAGATCTTCTTCAA. As shown in Supplemental Figure
S1 (https://figshare.com/s/8666baab8a72b98cf517), 50 and $75 \mathrm{n} M$ PGC-1 $\alpha$ siRNA could significantly inhibit mRNA abundance of PGC- $1 \alpha$ in calf hepatocytes. Thus, $50 \mathrm{n} M$ PGC-1 $\alpha$ siRNA was used in subsequent experiments.

\section{Western Blotting}

Total protein from hepatocytes was extracted according to manufacturer's instructions (Sangon Biotech Co., Ltd.). Protein concentrations were determined with the bicinchoninic acid protein assay reagent kit (P1511; Applygen Technologies Inc.). Subsequently, target proteins were separated by SDS-PAGE and then electrotransferred onto polyvinylidene fluoride membranes. Membranes were blocked with 3\% BSA in Tris-buffered saline/Tween buffer for $4 \mathrm{~h}$ at $25^{\circ} \mathrm{C}$. Then, blocked membranes were incubated overnight at $4^{\circ} \mathrm{C}$ with primary antibodies against PGC- $1 \alpha(1: 1,000$; ab54481; Abcam Co., Ltd.), COX4 (1:1,000; ab14744; Abcam), TFAM (1:1,000; APR36993-P050; Aviva Systems Biology Corporation), VDAC1 (1:1,000; ab15895; Abcam), and $\beta$-actin (1:2000; ab8226; Abcam). Membranes were then washed with Trisbuffered saline/Tween and incubated with horseradish peroxidase-conjugated anti-rabbit or anti-mouse immunoglobulin at $25^{\circ} \mathrm{C}$ for $45 \mathrm{~min}$. Immunoreactive bands were detected with an enhanced chemiluminescence solution (ECL, WBKLS0500; Millipore). Last, all bands were imaged using a ProteinSimple imager (ProteinSimple) and analyzed using Image-pro Plus (Media Cybernetics).

\section{Cell Viability Assay}

Cell viability was determined with the CCK-8 kit (CK04, Dojindo Co.) according to manufacturer's instructions. Cells were seeded at $5 \times 10^{3}$ cells/well in 96-well plates incubated at $37^{\circ} \mathrm{C}$ in $5 \% \mathrm{CO}_{2}$. After treatment, $20 \mu \mathrm{L}$ of CCK-8 solution was added to each well and then incubated for $4 \mathrm{~h}$ at $37^{\circ} \mathrm{C}$ in $5 \% \mathrm{CO}_{2}$. The optical density was measured at $450 \mathrm{~nm}$ on a spectrophotometer (Thermo Scientific Instruments Inc.). As shown in Supplemental Figure S2 (https://figshare .com/s/8666baab8a72b98cf517), propionate treatment did not affect cell viability.

\section{Quantitative Real-Time PCR}

Total RNA from hepatocytes was extracted using RNAiso Plus (9109; TaKaRa Biotechnology Co., Ltd.), and then quantified using a K5500 MicroSpectrophotometer (Beijing Kaiao Technology Development 
Ltd.). The RNA quality was assessed by electrophoresis (1\% agarose gels) using the gel loading solution (All-Purpose, Native Agarose, AM8556; Thermo Fisher Scientific). We generated cDNA from total RNA using a reverse transcription kit (RR047A; TaKaRa Biotechnology Co., Ltd.) and subsequently stored it at $-80^{\circ} \mathrm{C}$. We evaluated mRNA abundance using quantitative real-time PCR technology with the SYBR Green QuantiTect RT-PCR kit (RR420A; TaKaRa Biotechnology Co., Ltd.) and a 7500 Real-Time PCR System (Applied Biosystems Inc.). The quantitative real-time PCR was conducted with initial denaturation at $94^{\circ} \mathrm{C}$ for $2 \mathrm{~min}$, 35 cycles of amplification (denaturation at $94^{\circ} \mathrm{C}$ for 10 $\mathrm{s}$, annealing at $60^{\circ} \mathrm{C}$ for $15 \mathrm{~s}$, and extension at $72^{\circ} \mathrm{C}$ for $30 \mathrm{~s}$ ), and extension at $72^{\circ} \mathrm{C}$ for $5 \mathrm{~min}$. The relative abundance of each target gene was normalized to 2 reference genes, $A C T B$ and $G A P D H$, and calculated by a mathematical model, which included an efficiency correction for PCR efficiency (Pfaffl, 2001). The primers are listed in Supplemental Table S1 (https:// figshare.com/s/8666baab8a72b98cf517). Genes $A C T B$ and $G A P D H$ were stably expressed in different groups (Supplemental Figure S3, https://figshare.com/s/ 8666baab8a72b98cf517), and thus were deemed suitable as internal controls for normalization (Morey et al., 2011).

\section{Determination of Oxidative Stress Indices}

The ROS content in hepatocytes was determined with dichlorofluorescein diacetate (S0033S; Beyotime Biotechnology Inc.). Briefly, hepatocytes were incubated with dichlorofluorescein diacetate for $30 \mathrm{~min}$ at $37^{\circ} \mathrm{C}$. The fluorescence intensity of cells was measured by flow cytometry (CytoFLEX, Beckman Coulter) and laser confocal microscopy (FV500, Olympus). Superoxide dismutase (SOD; S0101; Beyotime Biotechnology Inc.) and glutathione peroxidase (GSH-Px; S0058; Beyotime Biotechnology Inc.) activities were measured using commercial kits. Malondialdehyde (MDA) content was measured using spectrophotometric diagnostic kits (BC0025; Solarbio Technology Co., Ltd).

\section{Apoptosis Assay}

In brief, hepatocytes were treated with $1.2 \mathrm{mM}$ fatty acids and $2 \mathrm{mM}$ propionate for $12 \mathrm{~h}$ with siRNA treatment. Hepatocytes were collected into centrifugal tubes then centrifuged at $1,000 \times g$ for 5 min at $4^{\circ} \mathrm{C}$. Subsequently, hepatocytes were separated by trypsin digestion and stained using Annexin V-fluorescein isothiocyanate/propidium iodide (556547; BD Biosciences) and then analyzed using flow cytometry.

\section{Laser Scanning Confocal Microscope Assay of Apoptosis}

Hepatocytes were treated with fatty acids $(1.2 \mathrm{mM})$, propionate $(2 \mathrm{mM})$, or both for $12 \mathrm{~h}$, and then samples were fixed with $4 \%$ (wt/vol) paraformaldehyde for 20 min, rinsed thrice in PBS, mounted with ProLong Diamond Antifade Mountant with 4',6-diamidino-2-phenylindole (D9542; Sigma-Aldrich), and rinsed thrice again. Last, the coverslips were sealed with glycerol, and samples were imaged using laser confocal microscopy (FV500, Olympus). At least 3 watching zones were selected for each sample using a laser scanning confocal microscope.

\section{MitoTracker Staining}

Mitochondria were detected using MitoTracker Red CMXRox (M7512; Invitrogen, Ltd.). The cell-permeant MitoTracker Red CMXRox probes contained a mildly thiol-reactive chloromethyl moiety for labeling mitochondria. Hepatocytes were incubated with $200 \mathrm{nM}$ MitoTracker Red CMXRox diluted in serum-free culture medium at $37^{\circ} \mathrm{C}$ for $30 \mathrm{~min}$. Subsequently, hepatocytes were washed thrice with PBS and the fluorescence intensity of cells were measured by flow cytometry (Becton Dickinson).

\section{Statistical Analysis}

All analyses were performed using GraphPad Prism 8.0 (Graph Pad Software) or SPSS (Statistical Package for the Social Science) 19.0 software (IBM). Linear and quadratic contrasts were conducted to evaluate doseand time-dependent effects. Data were analyzed using a one-way ANOVA followed by least significant difference (LSD) analysis. We considered $P<0.05$ significant and $P<0.01$ highly significant. Data throughout the text and figures are presented as means \pm standard error of the means.

\section{RESULTS}

\section{Propionate Enhanced Mitochondrial Function in Calf Hepatocytes}

Compared with controls, protein abundance of PGC$1 \alpha$ was greater with 2 and $4 \mathrm{~m} M$ propionate $(P<0.05$, Figure 1a and b). Protein abundance of TFAM and VDAC1 was greater with 1,2 , and $4 \mathrm{mM}$ propionate, whereas COX 4 was greater with 2 and $4 \mathrm{~m} M$ propionate $(P<0.05$, Figure $1 \mathrm{a}$ and $\mathrm{b})$. In addition, protein abundance of PGC-1 $\alpha$, TFAM, VDAC1, and COX4 in response to propionate increased over time, and both 
were greater at 12 and $24 \mathrm{~h}$ posttreatment $(P<0.05$, Figure 1c and d). Flow cytometry further showed that $2 \mathrm{~m} M$ propionate treatment increased the number of mitochondria in hepatocytes at 3 to $12 \mathrm{~h}$ postincubation $(P<0.05$, Figure $1 \mathrm{e}-\mathrm{n})$.

\section{Propionate Enhanced Mitochondrial Function Through PGC-1a}

Compared with the propionate treatment group, knockdown of PGC-1 $\alpha$ by siRNA markedly decreased a

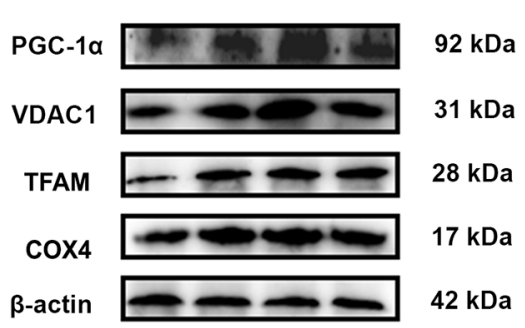

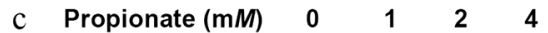

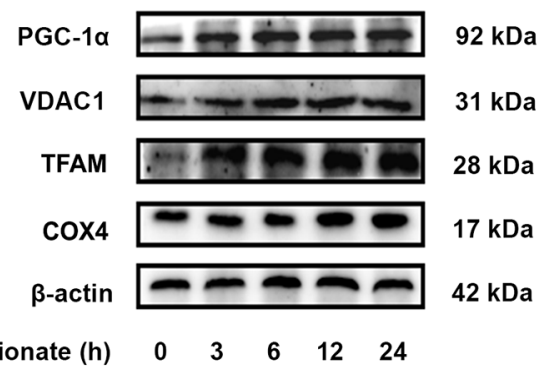

b

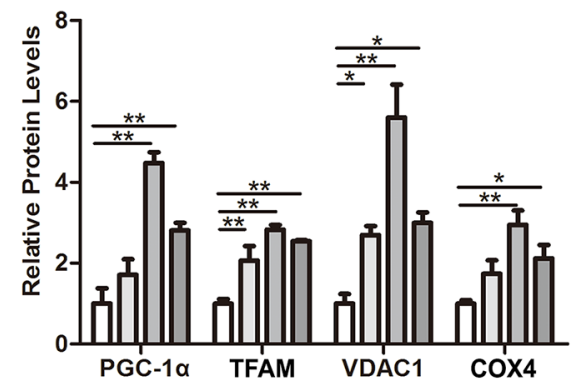

d
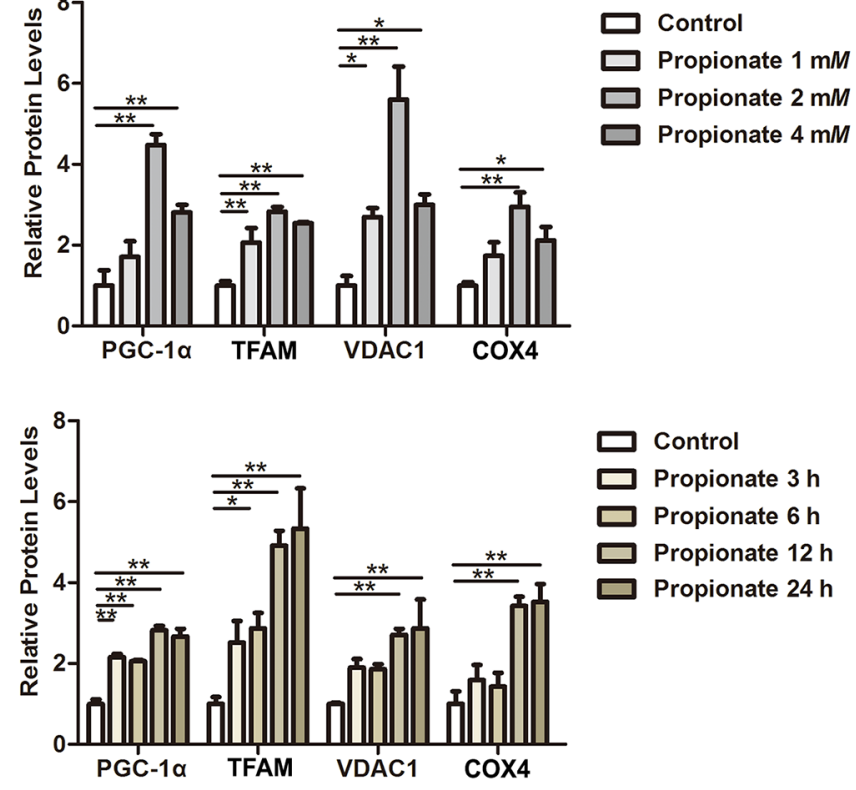
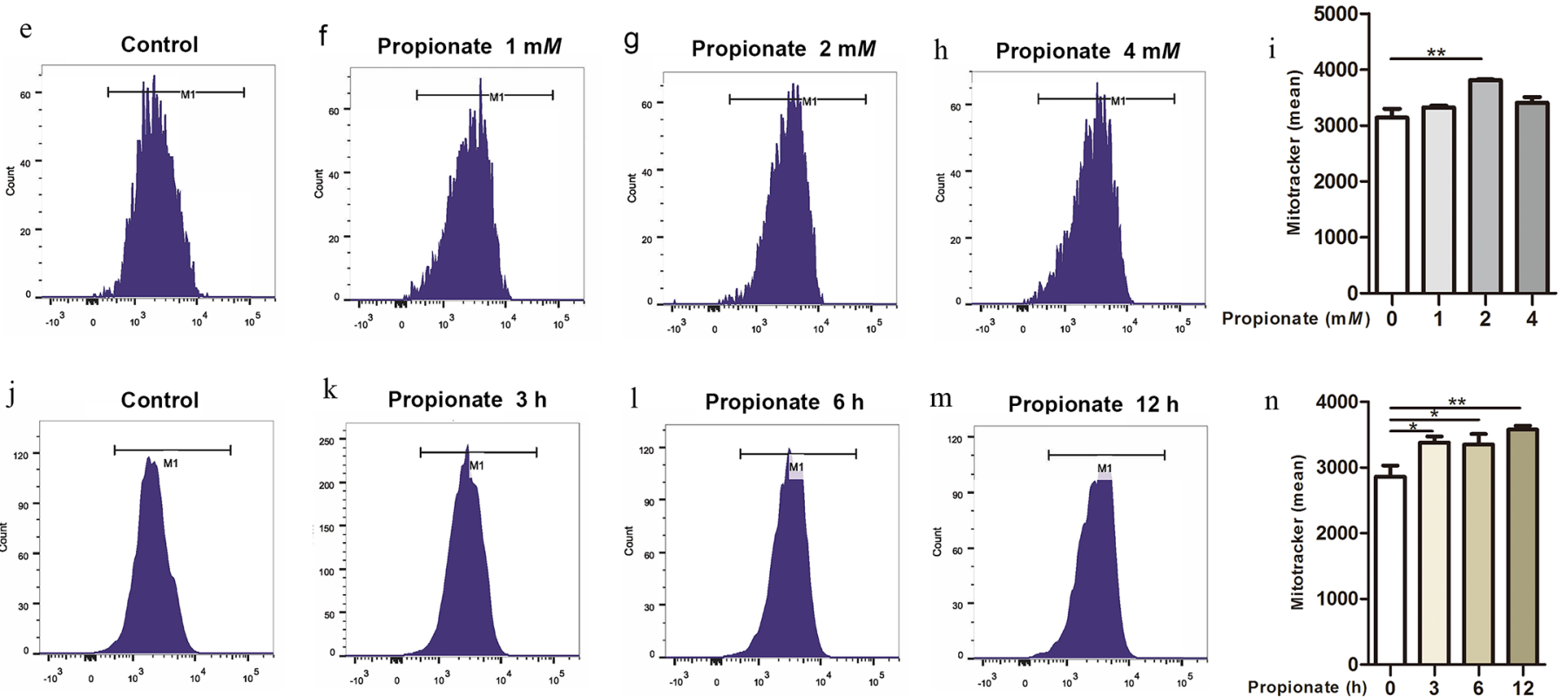

Figure 1. Propionate enhanced mitochondrial function in calf hepatocytes. (a) Representative blots of protein levels of PGC-1 $\alpha$, VDAC1, TFAM, COX4, and $\beta$-actin in calf hepatocytes treated with $0 \mathrm{~m} M, 1 \mathrm{~m} M, 2 \mathrm{~m} M$, and $4 \mathrm{~m} M$ of propionate for $12 \mathrm{~h}$. (b) Quantification of protein levels of PGC-1 $\alpha$, VDAC1, TFAM, and COX4. (c) Representative blots of protein levels of PGC-1 $\alpha$, VDAC1, TFAM, COX4, and $\beta$-actin in calf hepatocytes treated with $2 \mathrm{~m} M$ of propionate for $0 \mathrm{~h}, 3 \mathrm{~h}, 6 \mathrm{~h}, 12 \mathrm{~h}$ and $24 \mathrm{~h}$. (d) Quantification of protein levels of PGC-1 $\alpha$, VDAC1, TFAM, and COX4. (e-i) The number variation of mitochondria in calf hepatocytes treated with $0 \mathrm{~m} M, 1 \mathrm{~m} M, 2 \mathrm{~m} M$, and $4 \mathrm{~m} M$ of propionate for 12 $\mathrm{h}$. The mitotracker levels were represented by the mean of fluorescence density determined by flow cytometry. M1 is the positive mitotracker expression zone. $(\mathrm{j}-\mathrm{n})$ The number variation of mitochondria in calf hepatocytes treated with $2 \mathrm{~m} M$ propionate for different times $(0,3,6$, or $12 \mathrm{~h}$ ). Data were analyzed using a one-way ANOVA followed by LSD analysis. Data are expressed as the mean \pm SEM. ${ }^{*} P<0.05 ; * * P<0.01$. 
protein abundance of TFAM, VDAC1, and COX4 $(P$ $<0.05$, Figure 2a and b). Furthermore, the number of mitochondria was lower in the propionate + PGC-1 $\alpha$ siRNA group $(P<0.05$; Figure $2 \mathrm{c}-\mathrm{f})$.

\section{Propionate Attenuated Fatty Acid-Induced Mitochondrial Dysfunction and Oxidative Stress in Calf Hepatocytes}

Compared with the control group, protein abundance of PGC-1 $\alpha$, TFAM, VDAC1, and COX4 was lower in hepatocytes treated with $1.2 \mathrm{~m} M$ fatty acids $(P<0.05$; Figure 3a and b). The MDA content was greater, but SOD and GSH-PX activities were lower with fatty acid treatment $(P<0.05$; Figure $3 \mathrm{c}-\mathrm{e})$. Furthermore, laser confocal microscopy revealed that the fluorescence intensity of ROS was also greater in response to fatty acid treatment (Figure $3 \mathrm{f}$ and g). Compared with fatty acid treatment, the greater protein abundance of PGC- $1 \alpha$, TFAM, VDAC1, and COX4 and activities of SOD and GSH-PX, and lower ROS and MDA content in the fatty acid + propionate group indicated that propionate treatment improved fatty acid-induced mitochondrial damage and oxidative stress $(P<0.05$; Figure 3$)$.

\section{Propionate Alleviated Fatty Acid-Induced Apoptosis in Calf Hepatocytes}

Compared with the control group, apoptosis rate was greater in hepatocytes treated with fatty acids $(P<$ 0.05 ; Figure $4 \mathrm{a}, \mathrm{b}$, and e). It is noteworthy that propionate treatment in cells receiving fatty acids decreased apoptosis rate $(P<0.05$; Figure $4 \mathrm{~b}$, d, and $\mathrm{e})$. The 4',6-diamidino-2-phenylindole nuclear staining revealed that fatty acid treatment induced the karyorrhexis and karyolysis of the nucleus in calf hepatocytes, which was abolished by propionate treatment (Figure $4 \mathrm{f}-\mathrm{i}$ ). a

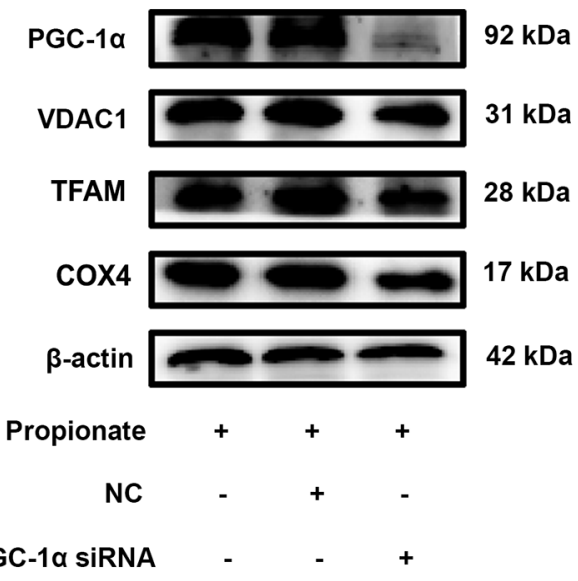

C

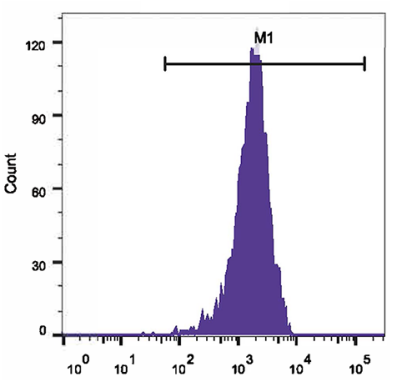

d

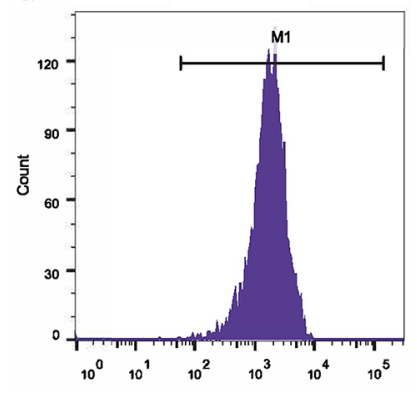

b

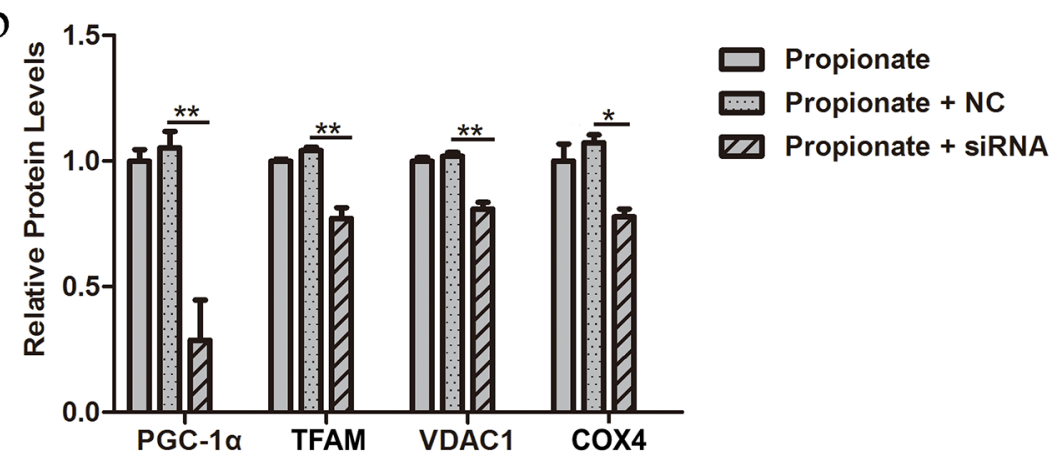

Figure 2. Propionate enhanced mitochondrial function through PGC-1 $\alpha$. Hepatocytes were infected with $50 \mathrm{n} M$ PGC-1 $\alpha$ small interfering RNA (siRNA; $48 \mathrm{~h}$ ) or negative control (NC) and treated with $2 \mathrm{~m} M$ propionate (12 h). (a) Representative blots of protein levels of PGC-1 $\alpha$, VDAC1, TFAM, COX4, and $\beta$-actin in calf hepatocytes. (b) Quantification of protein levels of PGC-1 $\alpha$, VDAC1, TFAM, and COX4. (c-f) The number variation of mitochondria in calf hepatocytes. The mitotracker levels were represented by the mean of fluorescence density determined by flow cytometry. M1 is the positive mitotracker expression zone. Data were analyzed using a one-way ANOVA followed by LSD analysis. Data were expressed as the mean \pm SEM. ${ }^{*} P<0.05 ;{ }^{* *} P<0.01$. 
a

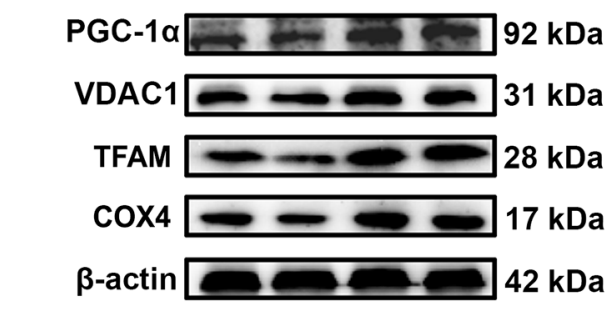

Fatty Acids $\quad-\quad+\quad-\quad+$

Propionate - $\quad+\quad+$

$\mathrm{C}$
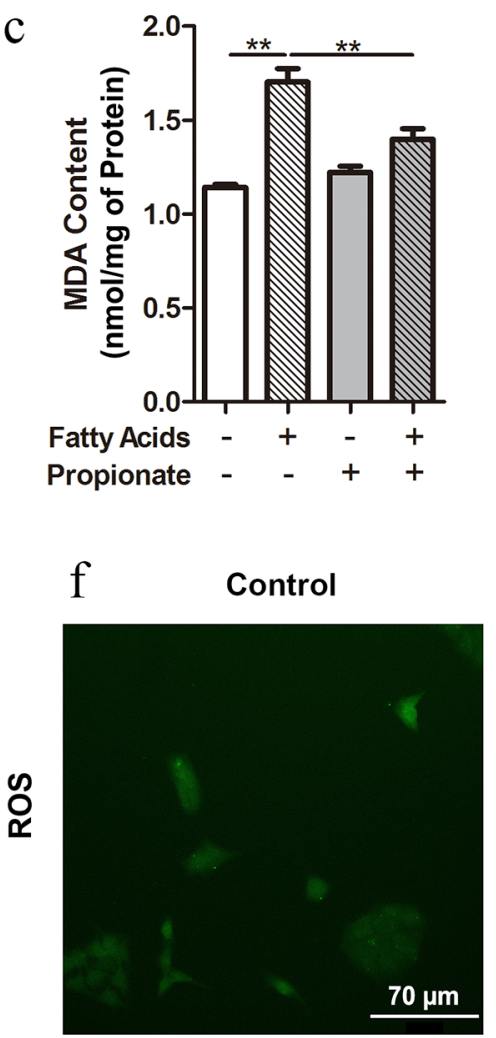

b

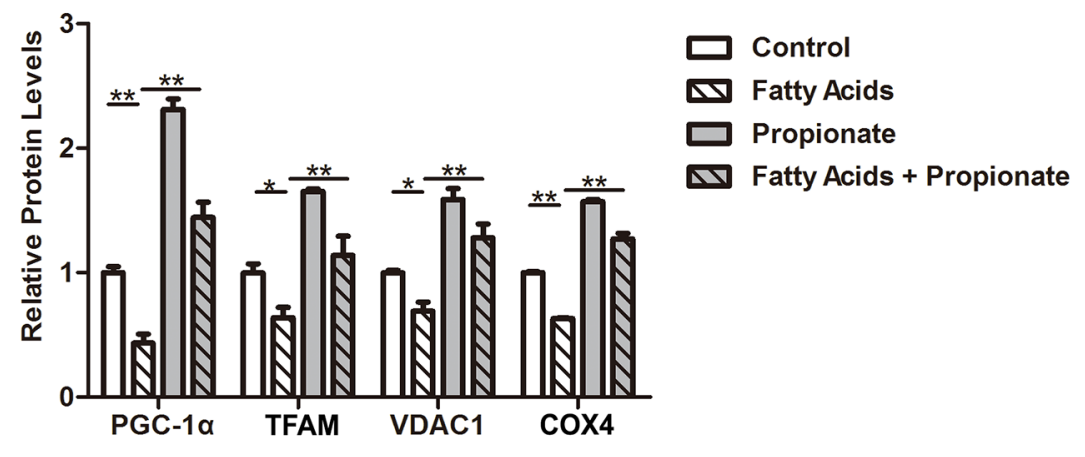

d

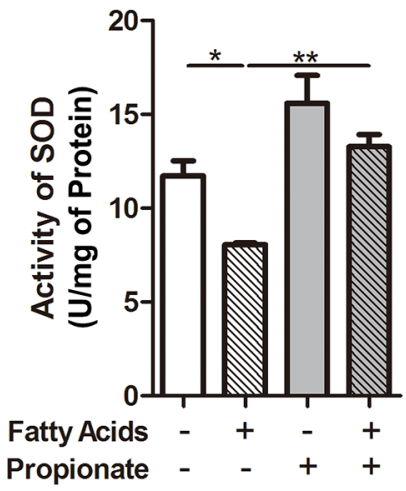

e

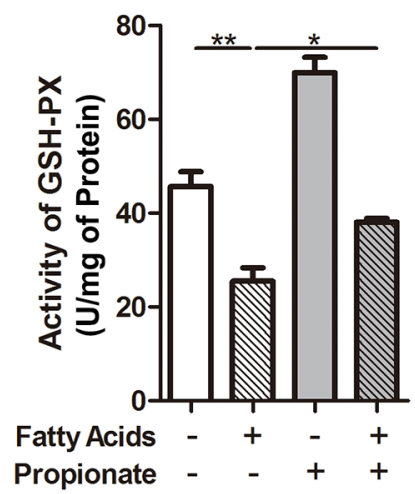

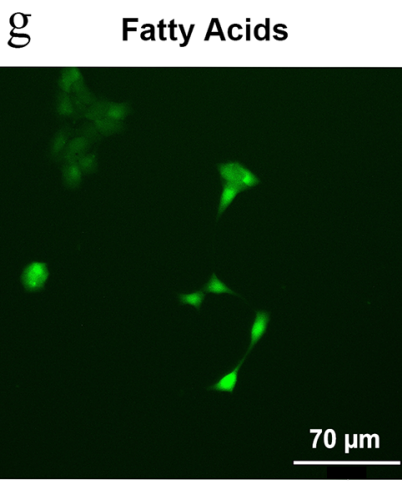

h Propionate

i Fatty Acids + Propionate
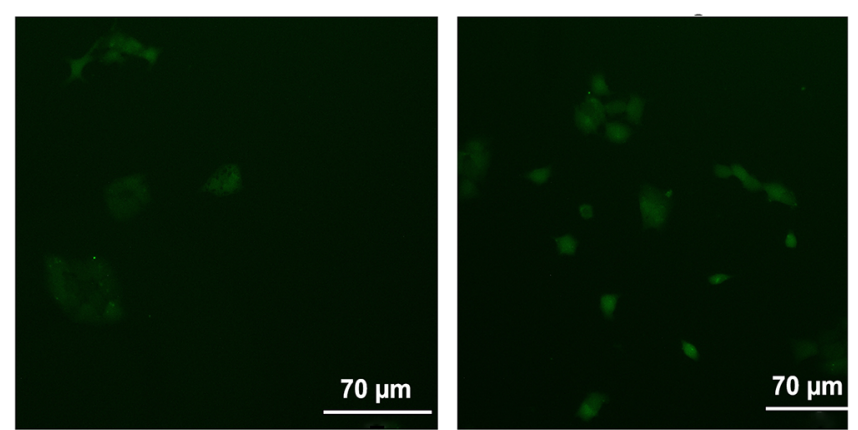

Figure 3. Propionate attenuated fatty acids-induced oxidative stress in calf hepatocytes. Hepatocytes were treated with or without $1.2 \mathrm{~m} M$ fatty acids, $2 \mathrm{mM}$ propionate, or both for $12 \mathrm{~h}$. (a) Representative blots of protein levels of PGC-1 $\alpha$, VDAC1, TFAM, COX4, and $\beta$-actin in calf hepatocytes. (b) Quantification of protein levels of PGC-1 $\alpha$, VDAC1, TFAM, and COX4. (c) The malondialdehyde (MDA) content. (d and e) The activity of sodium dismutase (SOD) and glutathione peroxidase (GSH-Px). (f-i) The reactive oxygen species (ROS) fluorescence images in hepatocytes determined by dichlorofluorescein diacetate. Data were analyzed using a one-way ANOVA followed by LSD analysis. Data were expressed as the mean \pm SEM. ${ }^{*} P<0.05$; ${ }^{* *} P<0.01$.

\section{Propionate Alleviated Mitochondrial Dysfunction, Oxidative Stress, and Apoptosis Through PGC-1a}

Compared with the fatty acid + propionate group, protein abundance of TFAM, VDAC1, and COX4 was lower in the fatty acid + propionate + PGC- $1 \alpha$ siRNA group $(P<0.05$; Figure 5a and b). However, ROS content and apoptosis rate were greater in the fatty acid + propionate + PGC-1 $\alpha$ siRNA group $(P<0.05$; Figure $5 \mathrm{c}-\mathrm{j})$.

\section{DISCUSSION}

During the transition from pregnancy to lactation, high producing dairy cows are at risk of developing ketosis. Cows with ketosis suffered from NEB and were 
characterized by high blood concentrations of fatty acids (Jorritsma et al., 2001; Grummer, 2008; Zhang et al., 2011). Overload of fatty acids not only can induce hepatic metabolic disorders, but also induce oxidative stress and apoptosis (Du et al., 2017), which further exacerbates the development of ketosis. Propionate and propylene glycol are widely-used in the prevention and treatment of ketosis (McNamara and Valdez, 2005; Kristensen and Raun, 2007; Maldini and Allen, 2018). Although previous studies provided mechanis- tic information on the positive effect of propionate, a glucose precursor, on NEB (McNamara and Huber, 2018), potential effects of fatty acid-induced hepatic pathological injury, oxidative stress, and apoptosis are not well known.

Mitochondria play indispensable roles in orchestrating hepatic energy homeostasis (Nassir and Ibdah, 2014; Rui, 2014). Its dysfunction is associated with the progression of hepatic metabolic disorders, a link that has been demonstrated in experimental models and a
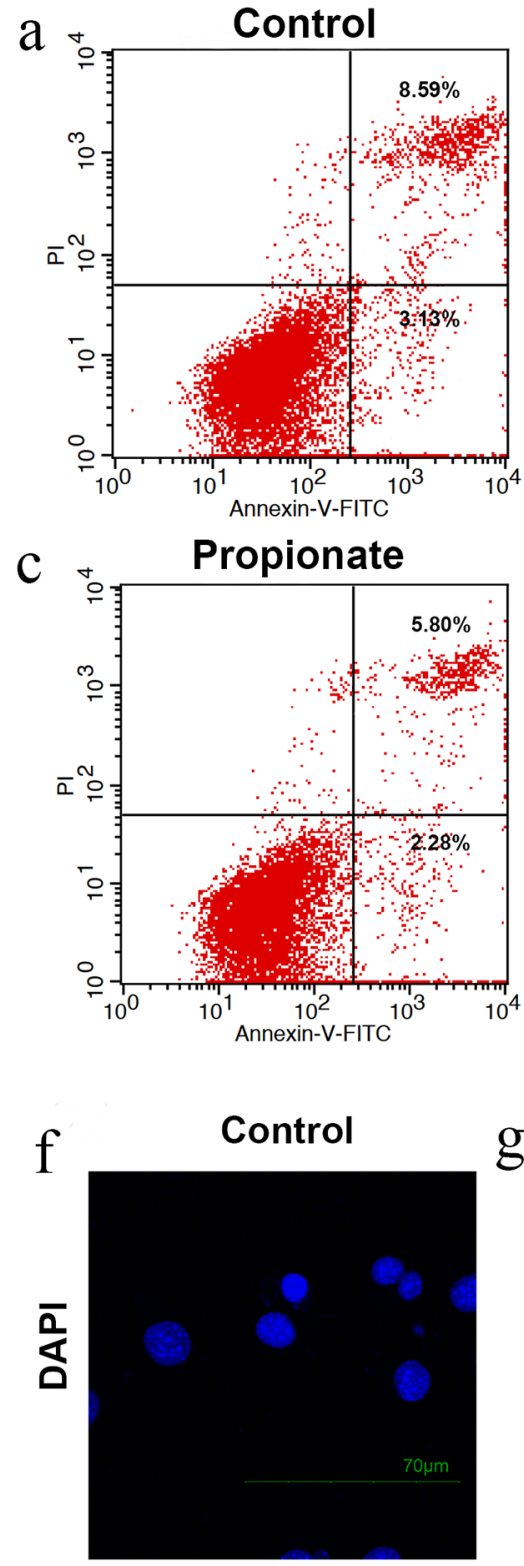

b
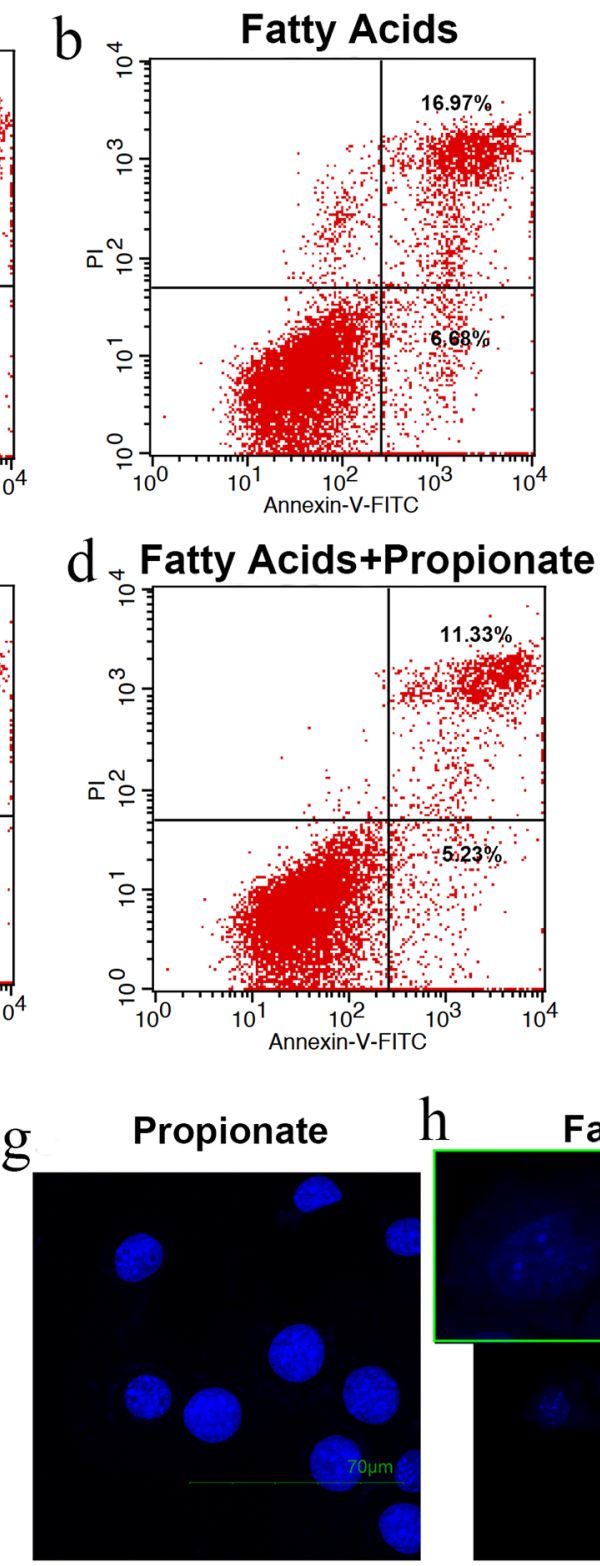

h

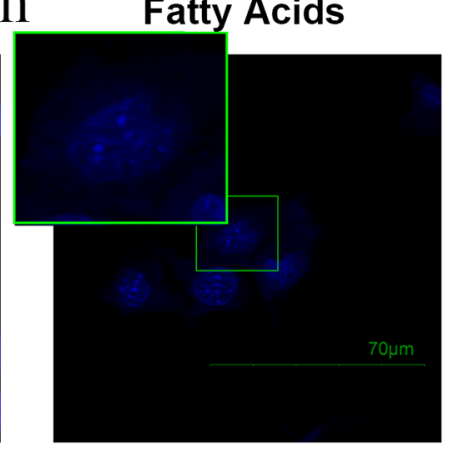

e

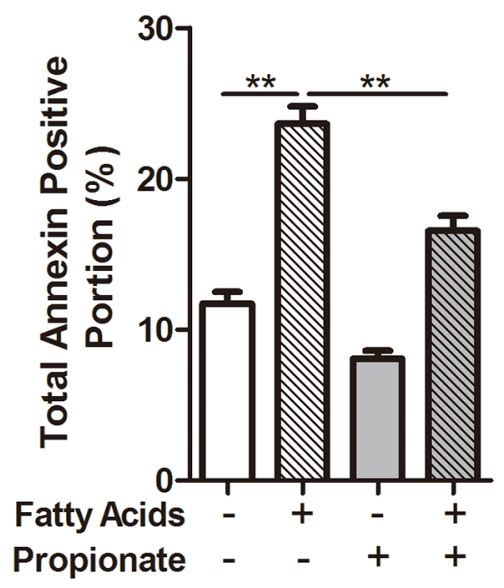

i

Figure 4. Propionate alleviated fatty acids-induced apoptosis in calf hepatocytes. Hepatocytes were treated with or without $1.2 \mathrm{~m} M$ fatty

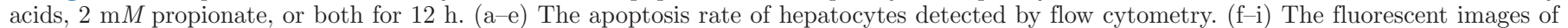

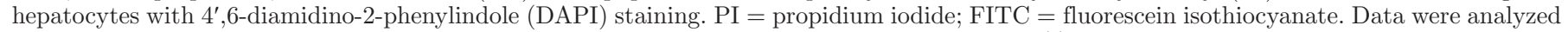
using a one-way ANOVA followed by LSD analysis. Data were expressed as the mean \pm SEM. $* * P<0.01$. 
dairy cows (Das et al., 2017; Gao et al., 2018; Buko et al., 2019). Impaired mitochondrial function leads to overproduction of ROS, which induces hepatic oxidative stress and cell damage and aggravates lipid accumulation. Importantly, high concentrations of fatty acids, a pathological factor for dairy cows with ketosis, are lipotoxic to induce mitochondrial dysfunction.
High concentrations of fatty acids resulted in markedly lower abundance of oxidative phosphorylation (OXPHOS) complexes I to V (COI-V) and impaired mitochondria structure in cow hepatocytes (Gao et al., 2018). The mitochondrial electron transport chain mediated by OXPHOS complexes is the main source of cellular ROS (Rolo et al., 2012). Defective protein
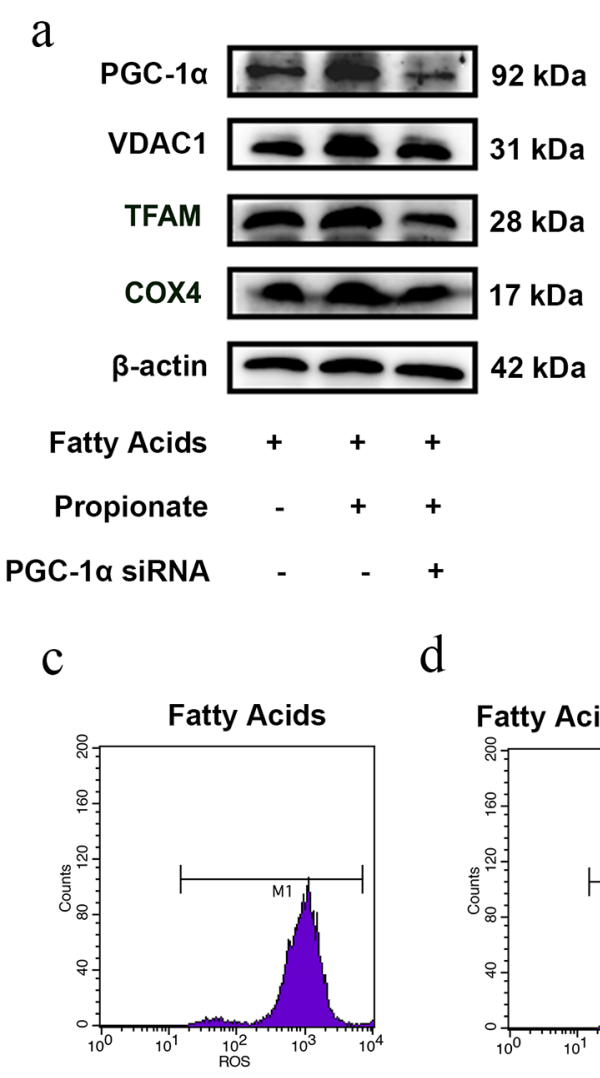

g

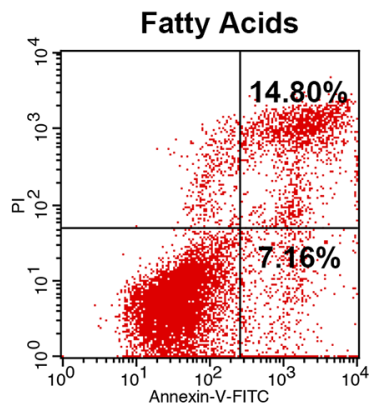

h b

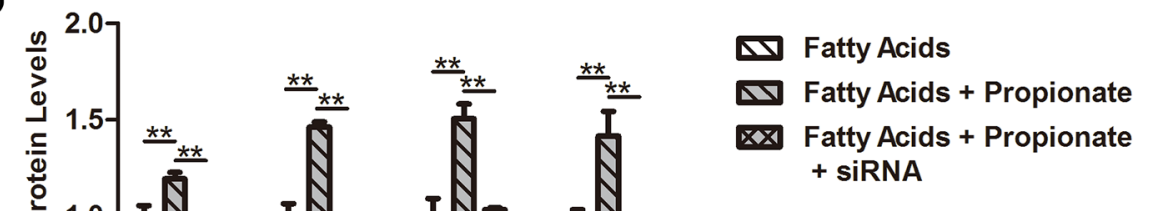

e

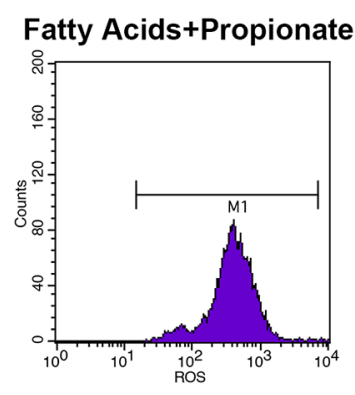

Fatty Acids+Propionate

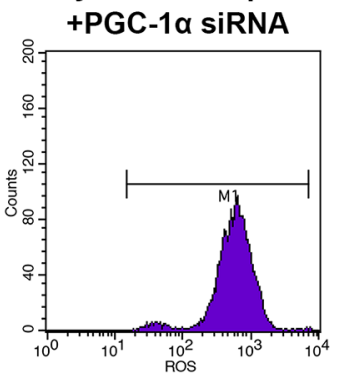

f
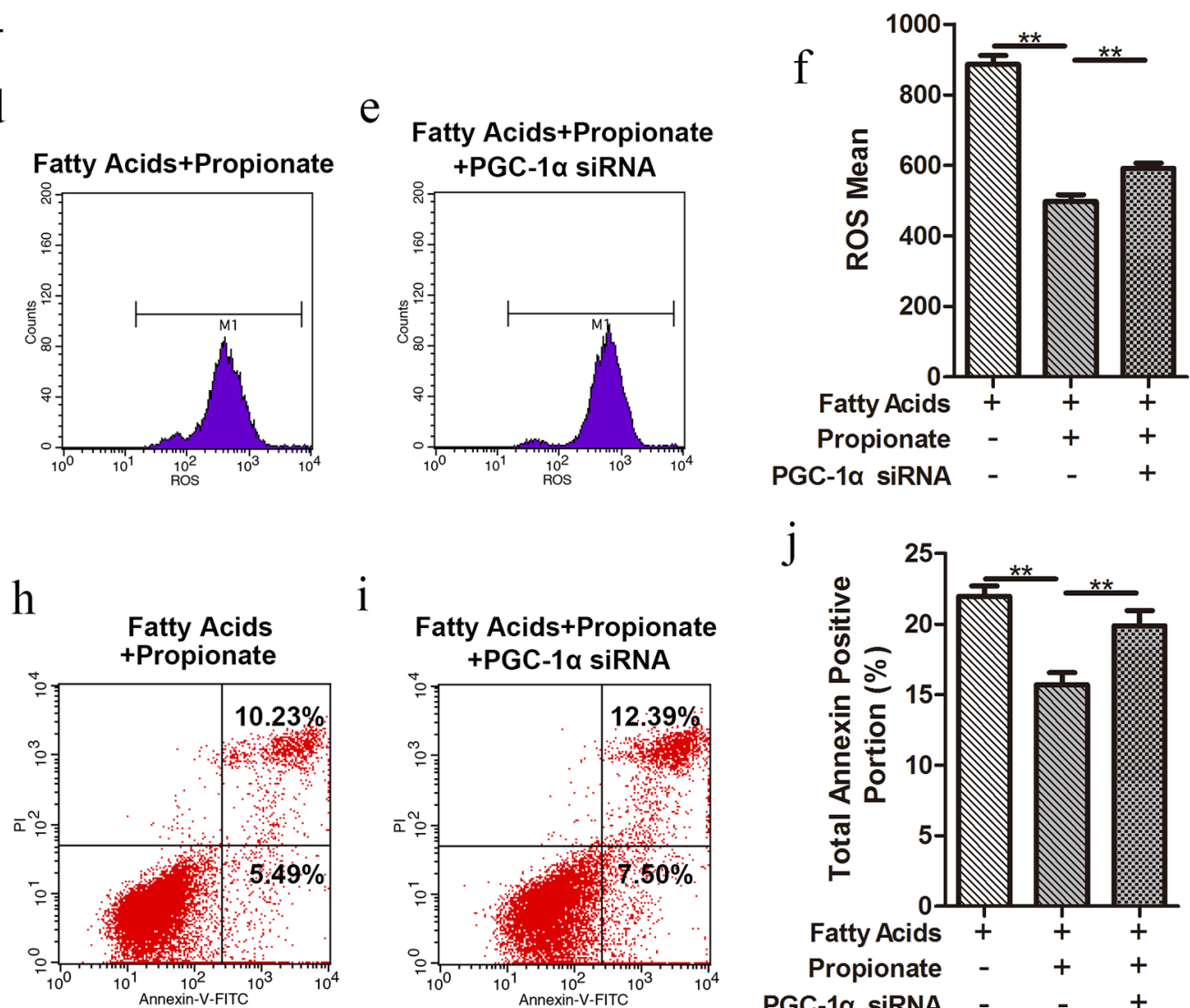

i

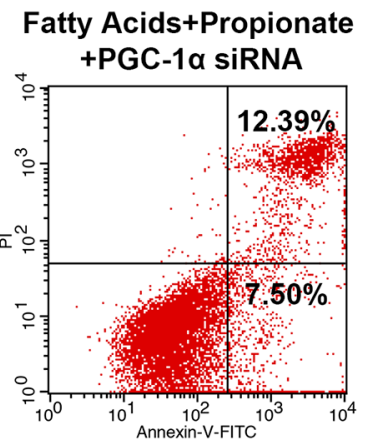

$\mathrm{j}$

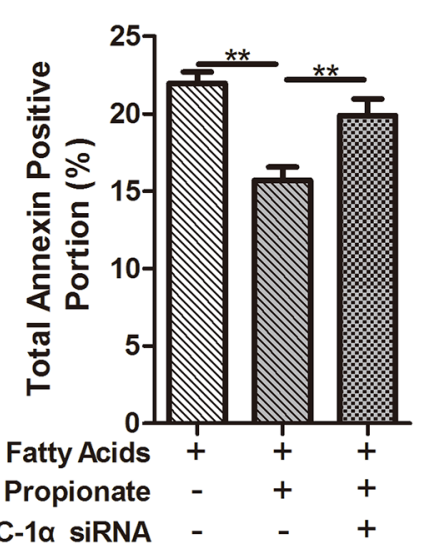

Figure 5. Propionate alleviated oxidative stress and apoptosis through PGC-1 $\alpha$. Hepatocytes treated with fatty acids (1.2 m $M, 12 \mathrm{~h})$, with or without $2 \mathrm{mM}$ propionate $(12 \mathrm{~h}$ ) only, or cotreated with $50 \mathrm{n} M$ PGC-1 $\alpha$ small interfering RNA (siRNA; $48 \mathrm{~h}$ ). (a) Representative blots of protein levels of PGC-1 $\alpha$, VDAC1, TFAM, COX4, and $\beta$-actin in calf hepatocytes. (b) Quantification of protein levels of PGC-1 $\alpha$, VDAC1, TFAM, and COX4. (c-f) Reactive oxygen species (ROS) content in hepatocytes was demonstrated by fluorescence intensity. ( $\mathrm{g}-\mathrm{j}$ ) The apoptotic rates of hepatocytes detected by flow cytometry. PI = propidium iodide; FITC = fluorescein isothiocyanate. Data were analyzed using a one-way ANOVA followed by LSD analysis. $* * P<0.01$. 
expression of complexes (COI-V) could induce a "leaky" transfer of electrons to molecular oxygen during OXPHOS, thus increasing ROS generation. Our study also showed that high concentrations of fatty acids impaired mitochondrial function and resulted in ROS overgeneration.

It is well known that excessive ROS directly damages DNA, proteins, and lipids and subsequently induces oxidative stress and apoptosis. In this study, the MDA content was greater in the fatty acid-treated calf hepatocytes than in control cells, whereas the activities of SOD and GSH-PX were lower. Furthermore, the apoptosis rate in hepatocytes was also greater in the fatty acid-treated group. Overall, these findings indicated that fatty acids impair mitochondrial function and induce oxidative stress and apoptosis, both of which can further aggravate cellular injury. Consequently, alleviating lipotoxicity induced by high concentrations of FFA in ketotic cows is an effective approach for preventing hepatic metabolic disorders and injury. Importantly, our in vitro data demonstrated that the improvement of mitochondrial dysfunction may be an important target for therapeutic strategies to alleviate ketosis.

Supplementation of propylene glycol, which is metabolized to propionate in the rumen or absorbed and used directly for the synthesis of glucose in the liver (Nielsen and Ingvartsen, 2004), to dairy cows after parturition is a common preventive treatment for NEB-induced shortfalls in circulating glucose that often lead to metabolic disorders (Zhang et al., 2016). Beyond its wellestablished role in gluconeogenesis, our previous data demonstrated that propionate alleviates endoplasmic reticulum stress and elevates cell viability in palmitic acid-treated calf hepatic cells by enhancing autophagy, which implies that propionate can directly ameliorate lipotoxicity in response to increased influx of palmitic acid into liver cells (Gao et al., 2021). The increased protein abundance of PGC- $1 \alpha$, VDAC1, TFAM, and COX4, and decreased oxidative stress and apoptosis rate in the present study demonstrated that propionate also could reduce the fatty acid-induced mitochondrial dysfunction in hepatocytes. Together with our previous studies, these findings further revealed additional biological mechanisms whereby propionate supply can alleviate hepatic damage in dairy cows during the transition period.

Protein PGC-1 $\alpha$ coordinates numerous genes needed for mitochondrial production by regulating the activity of several transcription factors, such as TFAM (Kelly and Scarpulla, 2004; Castrejón-Tellez et al., 2016). Reduced PGC-1 $\alpha$ protein abundance has been observed in the liver of cows with fatty liver, and its low abundance is associated with development of hepatic meta- bolic disorder and pathologic injury (Gao et al.,2018). Overexpression of PGC-1 $\alpha$ significantly decreased fatty acid-induced ROS overproduction in calf hepatocytes (Gao et al., 2018). Similarly, PGC-1 $\alpha$ overexpression increased mitochondrial function, reduced hepatic triacylglycerol content, and improved insulin resistance in primary murine hepatocytes (Morris et al., 2012), which further confirmed the beneficial role of PGC-1 $\alpha$ on mitochondrial dysfunction. The fact that propionate treatment increased abundance of PGC- $1 \alpha$ and reversed the negative effect of fatty acids on PGC- $1 \alpha$ expression in calf hepatocytes suggested that this protein mediated the observed effects of propionate. Intriguingly, silencing of PGC-1 $\alpha$ could abolish the positive effect of propionate on mitochondrial function and did not alleviate oxidative stress and apoptosis. Thus, taken together, our in vitro data suggested that propionate supply could diminish the negative effects of high fatty acid loads on mitochondrial function, oxidative stress state, and apoptosis via upregulating the expression of PGC-1 $\alpha$. Thus, PGC-1 $\alpha$ may be an attractive potential therapeutic target for the treatment of ketosis. Furthermore, propionate supply may alleviate hepatocyte injury by reducing ketone body production. Propionate is the main glycogenic progenitor of cow hepatocytes. When the supply of glycogenic precursors is insufficient, fatty acids are incompletely oxidized in hepatocytes and metabolized into ketone bodies. Conversely, an adequate supply of propionate blocks the above process, thereby reducing the harmful effect of ketone bodies to calf hepatocytes. This speculation needs further confirmation.

\section{CONCLUSIONS}

Propionate supply alleviates fatty acid-induced mitochondrial dysfunction, oxidative stress, and apoptosis by upregulating the abundance of the master regulator of mitochondrial function PGC-1 $\alpha$ in hepatocytes. As such, this protein may be a potential candidate for the prevention and treatment of ketosis. Accordingly, feeding sodium propionate and gavage of propylene glycol can supply glycogenic precursors and upregulate hepatic mitochondrial function mediated by PGC- $1 \alpha$ in perinatal cows, thereby reducing the risk of ketosis.

\section{ACKNOWLEDGMENTS}

This work was supported by the National Natural Science Foundation of China (Beijing, China; grant nos. 32022084 and 31772810) and the Fundamental Research Funds for the Central Universities (Changchun, China). The authors have not stated any conflicts of interest. 


\section{REFERENCES}

Aschenbach, J. R., N. B. Kristensen, S. S. Donkin, H. M. Hammon, and G. B. Penner. 2010. Gluconeogenesis in dairy cows: The secret of making sweet milk from sour dough. IUBMB Life 62:869-877. https://doi.org/10.1002/iub.400.

Bertics, S. J., R. R. Grummer, C. Cadorniga-Valino, and E. E. Stoddard. 1992. Effect of prepartum dry matter intake on liver triglyceride concentration and early lactation. J. Dairy Sci. 75:1914-1922. https://doi.org/10.3168/jds.S0022-0302(92)77951-X.

Bobe, G., J. W. Young, and D. C. Beitz. 2004. Invited review: Pathology, etiology, prevention, and treatment of fatty liver in dairy cows. J. Dairy Sci. 87:3105-3124. https://doi.org/10.3168/jds .S0022-0302(04)73446-3.

Buko, V., I. Kuzmitskaya, S. Kirko, E. Belonovskaya, E. Naruta, O. Lukivskaya, A. Shlyahtun, T. Ilyich, A. Zakreska, and I. Zavodnik. 2019. Betulin attenuated liver damage by prevention of hepatic mitochondrial dysfunction in rats with alcoholic steatohepatitis. Physiol. Int. 106:323-334. https://doi.org/10.1556/2060.106.2019 .26 .

Castrejón-Tellez, V., J. Rodríguez-Pérez, I. Pérez-Torres, N. PérezHernández, A. Cruz-Lagunas, V. Guarner-Lans, G. Vargas-Alarcón, and M. Rubio-Ruiz. 2016. The effect of resveratrol and quercetin treatment on PPAR mediated uncoupling protein (UCP-) 1 , 2, and 3 Expression in visceral white adipose tissue from metabolic syndrome rats. Int. J. Mol. Sci. 17:1069. https://doi.org/10.3390/ ijms17071069.

Das, N., A. Mandala, S. Naaz, S. Giri, M. Jain, D. Bandyopadhyay, R. J. Reiter, and S. S. Roy. 2017. Melatonin protects against lipidinduced mitochondrial dysfunction in hepatocytes and inhibits stellate cell activation during hepatic fibrosis in mice. J. Pineal Res. 62:e12404. https://doi.org/10.1111/jpi.12404.

Dong, J., J. J. Loor, R. Zuo, X. Chen, Y. Liang, Y. Wang, X. Shu, X. Sun, H. Jia, G. Liu, Z. Wang, X. Li, and X. Li. 2019. Low abundance of mitofusin 2 in dairy cows with moderate fatty liver is associated with alterations in hepatic lipid metabolism. J. Dairy Sci. 102:7536-7547. https://doi.org/10.3168/jds.2019-16544.

Du, X., L. Chen, D. Huang, Z. Peng, C. Zhao, Y. Zhang, Y. Zhu, Z. Wang, X. Li, and G. Liu. 2017. Elevated apoptosis in the liver of dairy cows with ketosis. Cell. Physiol. Biochem. 43:568-578. https: //doi.org/10.1159/000480529.

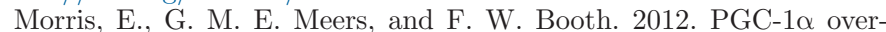
expression results in increased hepatic fatty acid oxidation with reduced triacylglycerol accumulation and secretion. Am. J. Physiol-Gastr. L. 303:G979-G992. https://doi.org/10.1152/ajpgi.00169 .2012

Gao, W., X. Du, L. Lei, H. Wang, M. Zhang, Z. Wang, X. Li, G. Liu, and X. Li. 2018. NEFA-induced ROS impaired insulin signalling through the JNK and p38MAPK pathways in non-alcoholic steatohepatitis. J. Cell. Mol. Med. 22:3408-3422. https://doi.org/10 $.1111 /$ jcmm.13617.

Gao, W., Z. Fang, L. Lei, L. Ju, B. Jin, J. J. Loor, Y. Liang, Z. Shi, T. Shen, H. Yu, M. Chen, H. Ouyang, Y. Song, Z. Wang, G. Liu, X. Li, and X. Du. 2021. Propionate alleviates palmitic acid-induced endoplasmic reticulum stress by enhancing autophagy in calf hepatic cells. J. Dairy Sci. 104:9316-9326. https://doi.org/10.3168/ jds.2020-19969.

Grummer, R. R. 2008. Nutritional and management strategies for the prevention of fatty liver in dairy cattle. Vet. J. 176:10-20. https:/ /doi.org/10.1016/j.tvjl.2007.12.033.

Hayirli, A., R. R. Grummer, E. V. Nordheim, and P. M. Crump. 2002. Animal and dietary factors affecting feed intake during the prefresh transition period in Holsteins. J. Dairy Sci. 85:3430-3443. https://doi.org/10.3168/jds.S0022-0302(02)74431-7.

Huc, L., A. Lemarie, F. Gueraud, and C. Helies-Toussaint. 2012. Low concentrations of bisphenol A induce lipid accumulation mediated by the production of reactive oxygen species in the mitochondria of HepG2 cells. Toxicol. In Vitro 26:709-717. https://doi.org/10 .1016/j.tiv.2012.03.017.

Jiang, X.-Y., D.-B. Lu, Y.-Z. Jiang, L.-N. Zhou, L.-Q. Cheng, and B. Chen. 2013. PGC-1 alpha prevents apoptosis in adipose-derived stem cells by reducing reactive oxygen species production in a diabetic microenvironment. Diabetes Res. Clin. Pract. 100:368-375. https://doi.org/10.1016/j.diabres.2013.03.036.

Jorritsma, R., H. Jorritsma, Y. H. Schukken, P. C. Bartlett, T. Wensing, and G. H. Wentink. 2001. Prevalence and indicators of post partum fatty infiltration of the liver in nine commercial dairy herds in The Netherlands. Livest. Prod. Sci. 68:53-60. https://doi .org/10.1016/S0301-6226(00)00208-6.

Kelly, D. P., and R. C. Scarpulla. 2004. Transcriptional regulatory circuits controlling mitochondrial biogenesis and function. Genes Dev. 18:357-368. https://doi.org/10.1101/gad.1177604.

Kim, H., J. H. Lee, and J.-W. Park. 2019. IDH2 deficiency exacerbates acetaminophen hepatotoxicity in mice via mitochondrial dysfunction-induced apoptosis. BBA-Mol. Biochim. Biophys. Acta Mol. Basis Dis. 1865:2333-2341. https://doi.org/10.1016/j.bbadis.2019 .05.012.

Koliaki, C., J. Szendroedi, K. Kaul, T. Jelenik, P. Nowotny, F. Jankowiak, C. Herder, M. Carstensen, M. Krausch, W. T. Knoefel, M. Schlensak, and M. Roden. 2015. Adaptation of hepatic mitochondrial function in humans with non-alcoholic fatty liver is lost in steatohepatitis. Cell Metab. 21:739-746. https://doi.org/10.1016/ j.cmet.2015.04.004.

Kristensen, N. B., and B. M. L. Raun. 2007. Ruminal and intermediary metabolism of propylene glycol in lactating Holstein cows. J. Dairy Sci. 90:4707-4717. https://doi.org/10.3168/jds.2007-0295.

Lee, J., J.-S. Park, and Y. S. Roh. 2019. Molecular insights into the role of mitochondria in non-alcoholic fatty liver disease. Arch. Pharm. Res. 42:935-946. https://doi.org/10.1007/s12272-019-01178-1.

Li, X., X. Li, G. Bai, H. Chen, Q. Deng, Z. Liu, L. Zhang, G. Liu, and Z. Wang. 2012. Effects of non-esterified fatty acids on the gluconeogenesis in bovine hepatocytes. Mol. Cell. Biochem. 359:385388. https://doi.org/10.1007/s11010-011-1032-x.

Li, Y., H. Ding, L. Liu, Y. Song, X. Du, S. Feng, X. Wang, X. Li, Z. Wang, X. Li, J. Li, J. Wu, and G. Liu. 2020. Non-esterified fatty acid induce dairy cow hepatocytes apoptosis via the mitochondriamediated ROS-JNK/ERK signaling pathway. Front. Cell Dev. Biol. 8:245. https://doi.org/10.3389/fcell.2020.00245.

Liu, L., X. Li, Y. Li, Y. Guan, Y. Song, L. Yin, H. Chen, L. Lei, J. Liu, X. Li, Z. Wang, X. Yang, and G. Liu. 2014. Effects of nonesterified fatty acids on the synthesis and assembly of very low density lipoprotein in bovine hepatocytes in vitro. J. Dairy Sci. 97:1328-1335. https://doi.org/10.3168/jds.2013-6654.

Maldini, G., and M. S. Allen. 2018. Temporal effects of ruminal propionic acid infusion on feeding behavior of Holstein cows in the postpartum period. J. Dairy Sci. 101:3077-3084. https://doi.org/ $10.3168 /$ jds.2017-13857.

McNamara, J. P., and K. Huber. 2018. Metabolic and endocrine role of adipose tissue during lactation. Annu. Rev. Anim. Biosci. 6:177195. https://doi.org/10.1146/annurev-animal-030117-014720.

McNamara, J. P., and F. Valdez. 2005. Adipose tissue metabolism and production responses to calcium propionate and chromium propionate. J. Dairy Sci. 88:2498-2507. https://doi.org/10.3168/ jds.S0022-0302(05)72927-1.

Miura, K., L. Yang, N. van Rooijen, D. A. Brenner, H. Ohnishi, and E. Seki. 2013. Toll-like receptor 2 and palmitic acid cooperatively contribute to the development of nonalcoholic steatohepatitis through inflammasome activation in mice. Hepatology 57:577-589. https://doi.org/10.1002/hep.26081.

Morey, S. D., L. K. Mamedova, D. E. Anderson, C. K. Armendariz, E. C. Titgemeyer, and B. J. Bradford. 2011. Effects of encapsulated niacin on metabolism and production of periparturient dairy cows. J. Dairy Sci. 94:5090-5104. https://doi.org/10.3168/jds.2011 -4304 .

Nassir, F., and J. A. Ibdah. 2014. Role of mitochondria in alcoholic liver disease. World J. Gastroenterol. 20:2136-2142. https://doi .org/10.3748/wjg.v20.i9.2136.

Nielsen, N. I., and K. L. Ingvartsen. 2004. Propylene glycol for dairy cows - A review of the metabolism of propylene glycol and its effects on physiological parameters, feed intake, milk production and risk of ketosis. Anim. Feed Sci. Technol. 115:191-213. https://doi .org/10.1016/j.anifeedsci.2004.03.008. 
Perier, C., J. Bove, and M. Vila. 2012. Mitochondria and programmed cell death in Parkinson's disease: Apoptosis and beyond. Antioxid. Redox Signal. 16:883-895. https://doi.org/10.1089/ars.2011.4074.

Pfaffl, M. W. 2001. A new mathematical model for relative quantification in real-time RT-PCR. Nucleic Acids Res. 29:e45. https://doi .org/10.1093/nar/29.9.e45.

Picca, A., and A. M. S. Lezza. 2015. Regulation of mitochondrial biogenesis through TFAM-mitochondrial DNA interactions: Useful insights from aging and calorie restriction studies. Mitochondrion 25:67-75. https://doi.org/10.1016/j.mito.2015.10.001.

Pingitore, A., E. S. Chambers, T. Hill, I. R. Maldonado, B. Liu, G. Bewick, D. J. Morrison, T. Preston, G. A. Wallis, C. Tedford, R. Castañera Gonzalez, G. C. Huang, P. Choudhary, G. Frost, and S. J. Persaud. 2017. The diet-derived short chain fatty acid propionate improves beta-cell function in humans and stimulates insulin secretion from human islets in vitro. Diabetes Obes. Metab. 19:257-265. https://doi.org/10.1111/dom.12811.

Pingitore, A., N. Gonzalez-Abuin, I. Ruz-Maldonado, G. C. Huang, G. Frost, and S. J. Persaud. 2019. Short chain fatty acids stimulate insulin secretion and reduce apoptosis in mouse and human islets in vitro: Role of free fatty acid receptor 2. Diabetes Obes. Metab. 21:330-339. https://doi.org/10.1111/dom.13529.

Rolo, A. P., J. S. Teodoro, and C. M. Palmeira. 2012. Role of oxidative stress in the pathogenesis of nonalcoholic steatohepatitis. Free Radic. Biol. Med. 52:59-69. https://doi.org/10.1016/j freeradbiomed.2011.10.003.

Rui, L. 2014. Energy metabolism in the liver. Compr. Physiol. 4:177197. https://doi.org/10.1002/cphy.c130024.
Zhang, Q., S. L. Koser, and S. S. Donkin. 2016. Propionate induces mRNA expression of gluconeogenic genes in bovine calf hepatocytes. J. Dairy Sci. 99:3908-3915. https://doi.org/10.3168/jds .2015-10312.

Zhang, Z., X. Li, G. Liu, L. Gao, C. Guo, T. Kong, H. Wang, R. Gao, Z. Wang, and X. Zhu. 2011. High insulin concentrations repress insulin receptor gene expression in calf hepatocytes cultured in vitro. Cell. Physiol. Biochem. 27:637-640. https://doi.org/10.1159/ 000330072.

Zhang, Z.-G., X.-B. Li, L. Gao, G.-W. Liu, T. Kong, Y.-F. Li, H.-B. Wang, C. Zhang, Z. Wang, and R.-H. Zhang. 2012. An updated method for the isolation and culture of primary calf hepatocytes. Vet. J. 191:323-326. https://doi.org/10.1016/j.tvj1.2011.01.008.

\section{ORCIDS}

Xinghui Wang @ https://orcid.org/0000-0001-9269-6161 Mengyao Zhu (i) https://orcid.org/0000-0001-8558-9886 Juan J. Loor @ https://orcid.org/0000-0003-1586-4365 Qianming Jiang () https://orcid.org/0000-0001-9522-4856 Xiliang Du (๑ https://orcid.org/0000-0002-1467-6998

Wenwen Gao @ https://orcid.org/0000-0003-4702-7596 Jianguo Wang @ $\odot$ https://orcid.org/0000-0003-2273-2539 Guowen Liu @ https://orcid.org/0000-0002-2672-6104

Xinwei Li ๑ https://orcid.org/0000-0002-0765-677X 